\title{
Glycosylation of TRPM4 and TRPM5 channels: molecular determinants and functional aspects
}

\author{
Ninda Syam, Jean-Sébastien Rougier ${ }^{\dagger}$ and Hugues Abriel*t \\ Department of Clinical Research, and Swiss National Centre of Competence in Research (NCCR) TransCure, University of Bern, Bern, Switzerland
}

\section{Edited by:}

Dieter Wicher, Max Planck Institute for Chemical Ecology, Germany

\section{Reviewed by:}

Elva Diaz, University of California,

Davis, USA

Grzegorz Owsianik, KU Leuven,

Belgium

\section{*Correspondence:}

Hugues Abriel, Department of

Clinical Research, and Swiss

National Centre of Competence in

Research (NCCR) TransCure,

University of Bern, Murtenstrasse

35, 3010 Bern, Switzerland

e-mail: hugues.abriel@dkf.unibe.ch

tThese authors should be

considered as co-senior authors of this study.
The transient receptor potential channel, TRPM4, and its closest homolog, TRPM5, are non-selective cation channels that are activated by an increase in intracellular calcium. They are expressed in many cell types, including neurons and myocytes. Although the electrophysiological and pharmacological properties of these two channels have been previously studied, less is known about their regulation, in particular their post-translational modifications. We, and others, have reported that wild-type (WT) TRPM4 channels expressed in HEK293 cells, migrated on SDS-PAGE gel as doublets, similar to other ion channels and membrane proteins. In the present study, we provide evidence that TRPM4 and TRPM5 are each N-linked glycosylated at a unique residue, Asn ${ }^{992}$ and Asn ${ }^{932}$, respectively. N-linked glycosylated TRPM4 is also found in native cardiac cells. Biochemical experiments using HEK293 cells over-expressing WT TRPM4/5 or N992Q/N932O mutants demonstrated that the abolishment of N-linked glycosylation did not alter the number of channels at the plasma membrane. In parallel, electrophysiological experiments demonstrated a decrease in the current density of both mutant channels, as compared to their respective controls, either due to the Asn to Gln mutations themselves or abolition of glycosylation. To discriminate between these possibilities, HEK293 cells expressing TRPM4 WT were treated with tunicamycin, an inhibitor of glycosylation. In contrast to $\mathrm{N}$-glycosylation signal abolishment by mutagenesis, tunicamycin treatment led to an increase in the TRPM4-mediated current. Altogether, these results demonstrate that TRPM4 and TRPM5 are both N-linked glycosylated at a unique site and also suggest that TRPM $4 / 5$ glycosylation seems not to be involved in channel trafficking, but mainly in their functional regulation.

Keywords: TRPM4, TRPM5, N-linked glycosylation, ion channels, regulation

\section{INTRODUCTION}

TRPM4, and its closest homolog TRPM5, are members of the transient receptor potential (TRP) ion channel gene family (Clapham et al., 2005; Ramsey et al., 2006). As with all TRP channels, they consist of tetramers of alpha subunits and each monomer contains six transmembrane segments. The selectivity filter is located in the loop connecting the fifth and sixth transmembrane domains. The cytoplasmic $\mathrm{N}$ - and C-termini contain a number of potential protein-protein interaction domains (Nilius et al., 2005b). TRPM4 and TRPM5 channels are both activated by an increase in intracellular calcium and are only permeable to monovalent cations, such as sodium and potassium. In humans, TRPM4 is expressed in many cell types (Nilius et al., 2004). The human TRPM4b long splice variant is the only form that has been shown to mediate ionic current in heterologous expression systems, whereas the role of the short splice TRPM4a variant remains unknown (Murakami et al., 2003; Nilius et al., 2004). In the present study, we investigated the functional splice variant TRPM4b (subsequently referred to as TRPM4) and its closest homolog TRPM5.

Thus, far, the roles of TRPM4 have mainly been studied in immune cells (Launay et al., 2004; Barbet et al., 2008; Shimizu et al., 2009), pancreatic beta cells (Cheng et al., 2007), arterial and venous smooth muscle cells (Gonzales et al., 2010; Simard et al., 2010), skeletal muscle cells (Kruger et al., 2008), adrenal gland chromaffin cells (Mathar et al., 2010), cardiac cells (Guinamard et al., 2006a,b; Demion et al., 2007; Guinamard, 2007; Mathar et al., 2013), and neuronal cells (Schattling et al., 2012; Kim et al., 2013). TRPM5 has been shown to play an important role in taste sensory cells (Zhang et al., 2007) and in neurons (Egorov et al., 2002, 2006; Teruyama et al., 2011). The importance of TRPM4 in disease has been underlined by the observation that many pathogenic genetic variants have been found in patients with cardiac conduction disorders (Abriel et al., 2012), and that TRPM4 knock-out mice develop less neurological alterations in a mouse model of multiple sclerosis (Schattling et al., 2012).

A growing number of studies show that post-translational modification of TRPM4, such as phosphorylation by PKC (Earley et al., 2007; Crnich et al., 2010) and SUMOylation, play a role in regulating their density at the plasma membrane (Kruse et al., 2009; Liu et al., 2010). In addition, TRPM4 Western blots show that it migrates in SDS-PAGE gels as two distinct bands, suggesting that it may be glycosylated (Amarouch et al., 2013; Woo et al., 2013b). Thus, far, the molecular determinants and the function of this glycosylation are only partially understood. 
In this work, we used HEK293 cells transiently transfected with either TRPM4 or TRPM5 to investigate whether these channel proteins are glycosylated, and to determine the functional consequences of this post-translational modification. Biochemical and pharmacological experiments using mutant forms of TRPM4/5 channels revealed a unique $\mathrm{N}$-glycosylation site close to the selectivity filter. Cell surface biotinylation experiments and patchclamp recording in whole cell configuration suggest that TRPM4 and TRPM5 glycosylation plays a role in their function as channel proteins rather than for their expression at the plasma membrane. The results of the present study confirm and expand previous results, but at the same time highlight several differences to a recent study by Woo et al. (2013a).

\section{EXPERIMENTAL PROCEDURES \\ PLASMIDS}

Two plasmids, human HA-TRPM4 WT (GenBank AF497623; Uniprot Q8TD43-1) and TRPM5 WT (GenBank NM_014555.3; Uniprot Q9NZQ8-1), were received from Dr. Bouvagnet (University of Lyon, France) and from Dr. Vennekens (University of Leuven, Belgium), respectively. The constructs were mutagenized using Quickchange II XL (Agilent, Santa Clara, California, USA), according to the manufacturer's protocol. The primer sequences $\left(5^{\prime}\right.$ to $\left.3^{\prime}\right)$ used for mutagenesis were as follows: S TRPM4 a2974c_c2976g TCATGGAGCACAGCCAGTGCTCGT CGGAGCC, AS TRPM4 a2974c_c2976g GGCTCCGACGAGCAC TGGCTGTGCTCCATGA, S TRPM5 a2794c_c2796g ATGA AGCCCGTGTGCAGTGCTCCACCCACCC, AS TRPM5 a2794c_ c2796g GGGTGGGTGGAGCACTGCACACGGGCTTCAT.

\section{TRANSFECTIONS}

For biochemical experiments, HEK293 cells were individually transiently transfected with the following plasmids: $240 \mathrm{ng}$ of HATRPM4 WT or HA-TRPM4 N992Q, $2 \mu \mathrm{g}$ of either TRPM5 WT or TRPM5 N932Q in a P100 dish (BD Falcon, Durham, North Carolina, USA), mixed with $30 \mu$ l of JetPEI (Polyplus transfection, Illkirch, France) and $250 \mu \mathrm{l}$ of $150 \mathrm{mM} \mathrm{NaCl}$. The cells were incubated for $48 \mathrm{~h}$ at $37^{\circ} \mathrm{C}$ with $5 \% \mathrm{CO}_{2}$. For electrophysiological studies, T25 cm $\mathrm{cm}^{2}$ flasks of HEK293 cells were transiently co-transfected using X-tremeGENE 9 DNA transfection mix reagent (Roche Diagnostics, IN, USA) with $0.3 \mu \mathrm{g}$ of WT, mutant TRPM4, or TRPM5 channels. These transfections included $0.2 \mu \mathrm{g}$ of cDNA encoding CD8 antigen as a reporter gene. Anti-CD8 beads(Dynal, Oslo, Norway) were used to identify transfected cells, and only CD8-displaying cells were analyzed.Cells were used $48 \mathrm{~h}$ after transfection.

\section{CELL SURFACE BIOTINYLATION ASSAYS}

Following $48 \mathrm{~h}$ of incubation, transiently transfected HEK293 cells previously washed twice with cold 1x PBS were treated with $0.5 \mathrm{mg} / \mathrm{ml} \mathrm{EZ-link}{ }^{\mathrm{TM}}$ Sulfo-NHS-SS-Biotin (Thermo Scientific, Rockford, Illinois, USA) in cold $1 \mathrm{X}$ PBS for $15 \mathrm{~min}$ at $4^{\circ} \mathrm{C}$. Subsequently, the cells were washed twice with $200 \mathrm{mM}$ Glycine in cold 1X PBS and twice with cold 1X PBS to inactivate and remove the excess biotin, respectively. The cells were then lysed with $1 \mathrm{X}$ lysis buffer [50 mM HEPES pH 7.4; $150 \mathrm{mM} \mathrm{NaCl} ; 1.5 \mathrm{mM}$ $\mathrm{MgCl}_{2} ; 1 \mathrm{mM}$ EGTA pH 8; 10\% Glycerol; 1\% Triton X-100;
1X Complete Protease Inhibitor Cocktail (Roche, Mannheim, Germany)] for $1 \mathrm{~h}$ at $4^{\circ} \mathrm{C}$. Cell lysates were centrifuged at 16,000 g, $4^{\circ} \mathrm{C}$ for $15 \mathrm{~min}$. Two milligrams of the supernatant were incubated with $50 \mu \mathrm{l}$ Streptavidin Sepharose High Performance beads (GE Healthcare, Uppsala, Sweden) for $2 \mathrm{~h}$ at $4^{\circ} \mathrm{C}$, and the remaining supernatant was kept as the input. The beads were subsequently washed five times with $1 \mathrm{X}$ lysis buffer before elution with $50 \mu \mathrm{l}$ of $2 \mathrm{X}$ NuPAGE sample buffer (Invitrogen, Carlsbad, California, USA) plus $100 \mathrm{mM}$ DTT at $37^{\circ} \mathrm{C}$ for $30 \mathrm{~min}$. These biotinylated fractions were analyzed as TRPM4 expressed at the cell surface. The input fractions, analyzed as total expression of TRPM4, were resuspended with 4X NuPAGE Sample Buffer plus $100 \mathrm{mM}$ DTT, yielding a concentration of $1 \mathrm{mg} / \mathrm{ml}$, and then incubated at $37^{\circ} \mathrm{C}$ for $30 \mathrm{~min}$.

\section{DEGLYCOSYLATION ASSAYS}

Deglycosylation with PNGase F and Endo H. HEK293 cells or homogenized human atrial samples were lysed with $1 \mathrm{X}$ lysis buffer [50 mM HEPES pH 7.4; $150 \mathrm{mM} \mathrm{NaCl} ; 1.5 \mathrm{mM}$ $\mathrm{MgCl}_{2} ; 1 \mathrm{mM}$ EGTA pH $8.0 ; 10 \%$ Glycerol; $1 \%$ Triton X-100; $1 \mathrm{X}$ Complete Protease Inhibitor Cocktail (Roche, Mannheim, Germany)] for $1 \mathrm{~h}$ at $4^{\circ} \mathrm{C}$. The lysates were then centrifuged at $16,000 \mathrm{~g}, 4^{\circ} \mathrm{C}$ for $15 \mathrm{~min}$. Forty micrograms of these lysates were denatured for $30 \mathrm{~min}$ at $37^{\circ} \mathrm{C}$ in the presence of $1 \mathrm{X}$ Glycoprotein denaturing buffer and bidistilled $\mathrm{H}_{2} \mathrm{O}$ in a total volume of $21 \mu \mathrm{l}$. Following this incubation, glycosylation mix was added [PNGase F mix: 1X G7 buffer, 1X NP40 and 1500 units PNGase F; Endo H mix: 1X G5 buffer and 3000 units Endo H (New England Biolabs, Ipswich, MA, USA)] to the denatured samples and incubated for $1 \mathrm{~h}$ at $37^{\circ} \mathrm{C}$. To stop the reaction, $10 \mu \mathrm{l}$ of $4 \mathrm{X}$ NuPAGE sample buffer (Invitrogen, Carlsbad, California, USA) plus 100 mM DTT were added to the deglycosylated samples. For deglycosylation on biotinylated samples, denaturation was performed after the $2 \mathrm{~h}$ incubation of whole cell lysates with streptavidin beads. After aspirating the lysate, $35 \mu \mathrm{l}$ of bidistillated $\mathrm{H}_{2} \mathrm{O}$ and $5 \mu \mathrm{l}$ of $10 \mathrm{X}$ Glycoprotein denaturing buffer were added prior to denaturation at $37^{\circ} \mathrm{C}$ for $30 \mathrm{~min}$. Following this incubation, the glycosylation mix (PNGase F mix: $6 \mu$ l 10X G7 buffer, $6 \mu l$ 10X NP40 and 2000 units PNGase F or Endo H mix: $6 \mu$ l 10X G5 buffer and 4000 units Endo $\mathrm{H}$ ) was added to the denatured samples and incubated for $1 \mathrm{~h}$ at $37^{\circ} \mathrm{C}$. The samples were subsequently washed five times with the same lysis buffer $\left(800 \mathrm{~g}, 4^{\circ} \mathrm{C}, 2 \mathrm{~min}\right)$ before elution with $50 \mu \mathrm{l}$ of $2 \mathrm{X}$ NuPAGE sample buffer plus $100 \mathrm{mM}$ DTT at $37^{\circ} \mathrm{C}$ for $30 \mathrm{~min}$. Human tissue acquisition was performed in accordance with the Institutional Review Board and individual patient consent was obtained.

\section{WESTERN BLOT}

Protein samples were analyzed on 9\% polyacrylamide gels, transferred with the TurboBlot dry blot system (Biorad, Hercules, CA, USA) and detected with anti-TRPM4 (generated by Pineda, Berlin, Germany), anti-TRPM5 ab154788 (Abcam, Cambridge, UK), anti-Na ${ }^{+} / \mathrm{K}^{+}$ATPase $\alpha 1$ ab7671 (Abcam, Cambridge, UK) and anti $\alpha$-actin A2066 (Sigma, St. Louis, Missouri, USA) antibodies using SNAP i.d. (Millipore, Billerica, MA, USA). The anti-TRPM4 antibody was generated by Pineda (Berlin, Germany) using the following peptide sequence: 
NH2-CRDKRESDSERLKRTSQKV-CONH2. A fraction of the antisera, which was subsequently used in this study, was then affinity purified.

\section{CELLULAR ELECTROPHYSIOLOGY}

Whole-cell currents were measured at room temperature $\left(22-23^{\circ} \mathrm{C}\right)$ using a VE-2 (Alembic Instruments) amplifier. Pipette solution contained (in mM): 100 CsAspartate, $20 \mathrm{CsCl}$, $4 \mathrm{Na}_{2} \mathrm{ATP}, 1 \mathrm{MgCl}_{2}$, and 10 HEPES. The $\mathrm{pH}$ was adjusted to 7.2 with $\mathrm{CsOH}$, and the $\mathrm{Ca}^{2+}$ free concentration ranged to $100 \mu \mathrm{M}$ calculated by WEBMAXCLITE program (http://www. stanford.edu/ $\sim$ cpatton/downloads.htm). Bath solutions contained (in $\mathrm{mM}$ ): $156 \mathrm{NaCl}, 1.5 \mathrm{CaCl}_{2}, 1 \mathrm{MgCl}_{2}, 6 \mathrm{CsCl} 10$ $\mathrm{D}$-glucose, and 10 HEPES. The $\mathrm{pH}$ was adjusted to 7.4 with $\mathrm{NaOH}$. Data were analyzed using pClampsoftware, version 10.2 (Axon Instruments, Union City, California, USA).

\section{DRUGS}

Tunicamycin was purchased from Sigma-Aldrich (Sigma-Aldrich, Dorset, United Kingdom) and was dissolved in DMSO. DMSO did not exceed $0.1 \%$ in the final solution.

\section{STATISTICAL ANALYSIS}

Data are presented as mean \pm s.e.m. Unpaired, two-tailed Student's $t$-test was used to compare the means; $p<0.05$ was considered significant.

\section{RESULTS}

\section{TRPM4 CHANNEL IS N-LINKED GLYCOSYLATED AT Asn ${ }^{992}$}

As membrane proteins are often glycosylated and TRPM4 was migrating as a distinct doublet on SDS-PAGE gels, TRPM4 was then searched for the presence of an $\mathrm{N}$-glycosylation consensus sequence Asn-Xaa-Ser/Thr (Xaa being any amino acid except Pro and Asp), using the publicly available programme NetNGlyc 1.0 Server (http://www.cbs.dtu.dk/services/ NetNGlyc). A putative N-glycosylation motif, Asn-Cys-Ser at residue $\mathrm{Asn}^{992}$ (Figure 1A), located after the selectivity filter (981-EDMDVA-986) between segment 5 and 6 (Figure 1B), was detected. This consensus sequence is conserved in humans, mice, and rats (Figure 1A), while among other TRPM channels, only TRPM5 displays a similar signal at residue $\operatorname{Asn}^{932}$ (Figures 1A,B). To test the hypothesis that $\mathrm{Asn}^{992}$ is the TRPM4 glycosylation site, Asn was mutated into Gln (N992Q) to enable the investigation of the cell biology and functional roles of TRPM4 glycosylation. As illustrated in Figure 2, WT TRPM4 runs as a distinct doublet (Figure 2A) in Western blot experiments. The N992Q mutation resulted in a single band running faster than the lower band of the WT protein (compare lanes 3 and 5 in Figure 2A). This band was unaffected by treatment with Peptide-N-glycosidase F (PNGase F), which trims all N-linked glycosylation modifications (Figure 2A lane 6). Thus, this band was subsequently named unglycosylable TRPM4. Upon treatment with PNGase F, the two bands seen in the WT were also shifted into a single band running at the same height as the unglycosylable band (compare lanes 4 and 5 in Figure 2A). This observation led us to conclude that the upper and lower bands are fully- and core glycosylated TRPM4 fractions, respectively, and that $\mathrm{Asn}^{992}$ is the unique glycosylation site of TRPM4. The lanes where lysates of nontransfected HEK293 cells were loaded (empty in Figure 2A) show similar findings as the WT, albeit with much fainter signals. These bands are most likely endogenous TRPM4 expressed in HEK293 cells, as previously reported by our group (Amarouch et al., 2013). To further confirm that glycosylated TRPM4 exists in vivo, total protein from a piece of human cardiac atria was isolated and treated with PNGase F. As demonstrated in Figure 2B, endogenous cardiac TRPM4 ran as a distinct doublet (lane 1), which shifted into a single band (lane 2) running slightly lower than the core glycosylated band when treated with PNGase F. This result demonstrated that fully- and core glycosylated forms of TRPM4 are endogenously expressed in cardiac cells.

\section{GLYCOSYLATION IS NOT ESSENTIAL FOR THE EXPRESSION OF TRPM4 AT THE CELL SURFACE}

To determine whether glycosylation is essential for TRPM4 transport and expression at the cell surface, cell surface biotinylation assays were performed. As shown in Figure 2C (lanes 3 and 6), TRPM4 N992Q mutant was well expressed both in the whole cell lysate and at the cell surface, despite being unglycosylated (Figure 2C). This experiment suggests that glycosylation is not essential for expression of TRPM4 at the cell surface.

\section{TRPM4 N-GLYCOSYLATION TYPES ARE DIFFERENT IN THE INTRACELLULAR FRACTION AND AT THE CELL SURFACE}

In order to obtain more information about the $\mathrm{N}$-glycosylation identity of TRPM4, TRPM4 was treated with endoglycosidase $\mathrm{H}$ (Endo $\mathrm{H}$ ) in addition to PNGase F. While PNGase $\mathrm{F}$ trims all N-linked glycosylation (high mannose, hybrid and complex oligosaccharides) from the innermost GlcNAc (N-Acetylglucosamine) that is linked to an Asn residue, Endo H only trims high mannose and certain hybrid oligosaccharides, but not complex oligosaccharides (Maley et al., 1989). As illustrated in Figure 2D, PNGase F completely trims TRPM4 in total and biotinylated fractions (Figure 2D lanes 4 and 8). However, Endo $\mathrm{H}$ only trims a part of glycosylated TRPM4 in the input fraction (Figure 2D lane 3), and none in the biotinylated fraction (Figure 2D lane 7). This observation suggests that TRPM4 has a significant amount of complex oligosaccharides and a minor amount of high mannose and/or hybrid oligosaccharides in the total fraction where TRPM4 is mostly intracellular, while only complex oligosaccharides exist at the cell surface.

\section{THE N9920 MUTANT DECREASES TRPM4 CURRENT DENSITY}

Amarouch et al. (2013) used the patch clamp technique in wholecell configuration with HEK293 cells, to demonstrate that the TRPM4-mediated current recorded over time shows two distinct phases (Figure 3A). A transient phase appears quickly after the rupture of the membrane patch, and then a plateau phase appears 1-3 min later (Figure 3A). To investigate the consequences of the N992Q mutation on TRPM4 function, the transient and plateau current density were recorded at $+100 \mathrm{mV}$ and $-100 \mathrm{mV}$ using a ramp protocol (Figure 3B). The quantification of both groups (WT and N992Q) showed a statistically significant decrease in current density of both the transient and plateau phases (WT vs. N992Q transient: $161 \pm 38 \mathrm{pA} / \mathrm{pF} n=8$ vs. $27 \pm 7 \mathrm{pA} / \mathrm{pF}$ 


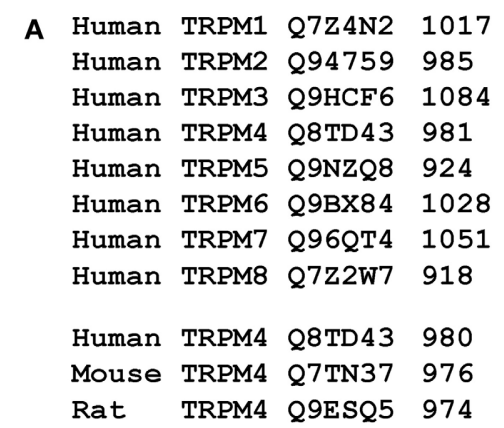

DQIDLYAME INPPCGEN-LYDEEGK-----RLPPCI--PGAWLTPALMACYLLVANILLVN Y-IDGVNFNPE-HCSPN-GTDPYKPKCPESDATQQRPAFPEWLTVLLLCLYLLFTNILLLN DQIDPP-------CGQN-ETREDGK-II-QLPPCK---TGAWIVPAIMACYLLVANILLVN EDMDVALMEHS NCSSEPGFWAHPP-GA--QAGTCVSQYANWLVVLLLVIFLLVANILLVN DE IDEARV--- NCSTHPLLLEDSP--------SCPSLYANWLVILLLVTFLLVTNVLLMN GE IDVCSSQ-------------P-------SCP--PGSFLTPFLQAVYLFVQY I IMVN YEIDVCANDS------------VIPQ-------ICG--PGTWLTPFLQAVYLFVQYIIMVN D-VDGTTYDFA-HCTFT-G-NESKPLCVELDE-HNLPRFPEWITIPLVCIYMLSTNILLVN QEDMDVALMEH\$NCSSEPGFWAHPPG QEEMDVALMIPQNCSMERGSWAHPEG QEEMDVALMNP@NCSAERGSWAHPEG

B

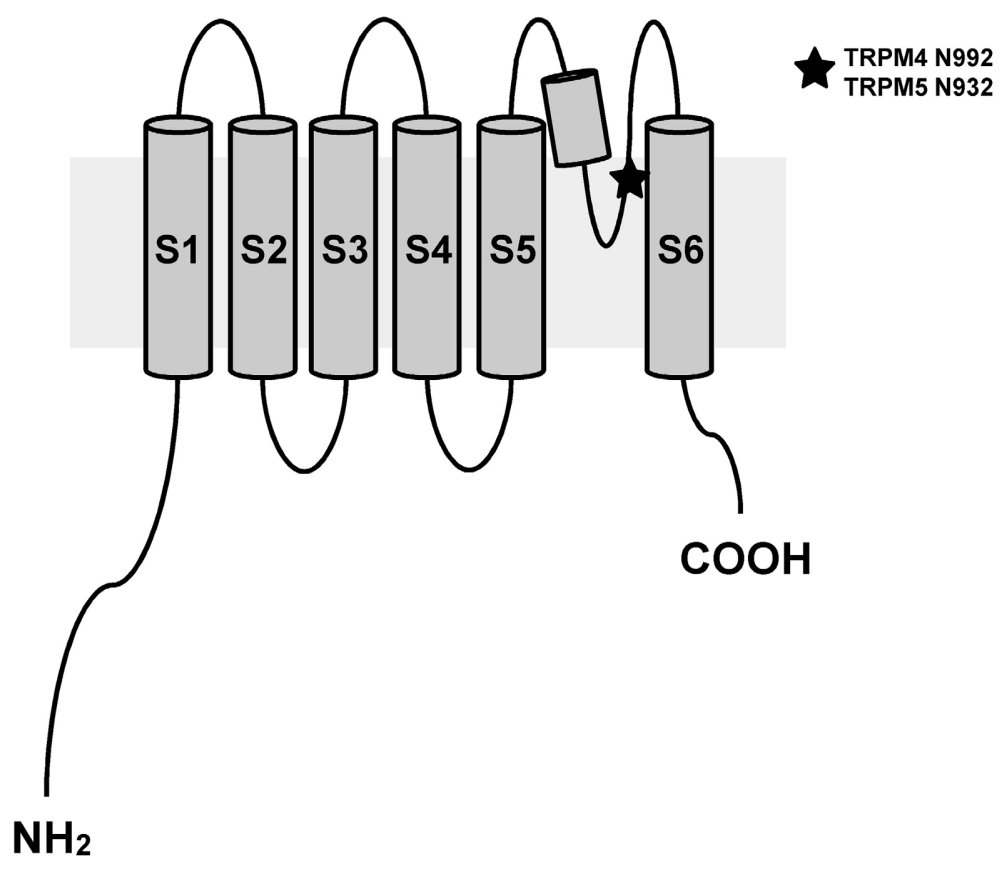

FIGURE 1 | $\mathrm{N}$-glycosylation site of TRPM4 and TRPM5. (A) A bioinformatic search reveals a putative site for N-linked glycosylation in TRPM4 that is conserved in different organisms and the closely related TRPM5.
(B) Illustration showing the location of N-linked glycosylation site in the pore-forming region between transmembrane segments 5 and 6 of TRPM4 and TRPM5. $n=6$; plateau: $604 \pm 53 \mathrm{pA} / \mathrm{pF} n=8$ vs. $327 \pm 62 \mathrm{pA} / \mathrm{pF} n=6)$ (Figures 3B,C). In addition, the deactivation kinetics of TRPM4 at the end of the step at $+100 \mathrm{mV}$ and $-100 \mathrm{mV}$ were faster with the N992Q mutant compared to WT (Figure 3B). Due to the extremely fast deactivation at $-100 \mathrm{mV}$, this parameter was only quantified at $+100 \mathrm{mV}$ (WT $3749 \pm 471 \mathrm{pA} / \mathrm{s} n=9$ vs. $\mathrm{N} 992 \mathrm{Q}-90 \pm 139 \mathrm{pA} / \mathrm{s} n=8, p<0.05)$. In parallel, the currentvoltage $(\mathrm{I}-\mathrm{V})$ relationship, performed during the plateau phase, did not reveal any drastic alterations in the voltage-dependence of the mutant channel (Figure 3D).

\section{TRPM5 CHANNEL IS N-LINKED GLYCOSYLATED AT Asn ${ }^{932}$}

Similar experiments were performed with TRPM5, since it is the closest relative of TRPM4 in the TRPM channel family and it has a similar N-glycosylation signal, Asn-Cys-Ser, at residue $\mathrm{Asn}^{932}$ (Figure 1A). To test the hypothesis that $\mathrm{Asn}^{932}$ is where the glycoside residues link to TRPM5, Asn was mutated into
Gln (N932Q). Using the same SDS-PAGE running conditions as for TRPM4, a lower band and a smeary upper band, presumably the core- and fully glycosylated bands, respectively, were observed with WT TRPM5 (Figure 4A lane 3). At the same time, the TRPM5 N932Q mutant appeared as a single band running faster than the lower band of the WT (Figure 4A lane 5), and this was concluded to be the unglycosylable band. When treated with PNGase F, the WT bands shifted into a single band (Figure 4A lane 4) running at the same height as the mutant band. This result confirms that $\mathrm{Asn}^{932}$ is the unique $\mathrm{N}$-glycosylation site of TRPM5, and that the upper and lower bands are the fully- and core glycosylated bands of TRPM5, respectively.

\section{GLYCOSYLATION IS NOT ESSENTIAL FOR THE EXPRESSION OF TRPM5 AT THE PLASMA MEMBRANE}

After concluding that glycosylation of TRPM4 is not essential for its expression at the cell surface, tests were performed to 


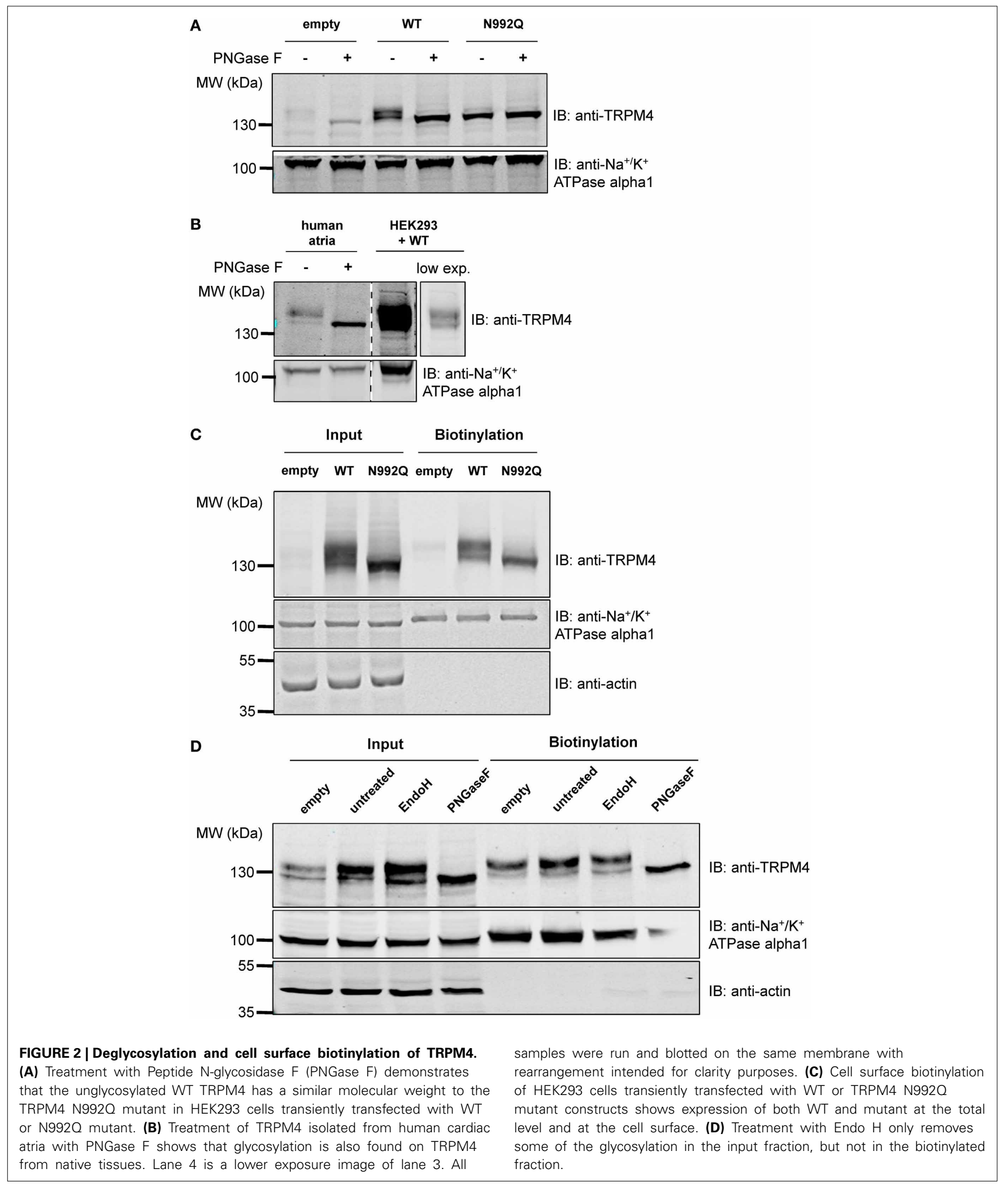

determine if this was also the case for TRPM5. Despite being unglycosylated, the TRPM5 N932Q mutant was well expressed and could be found in both the total fraction as well as the cell surface (Figure 4B lanes 3 and 6 ). This suggests that glycosylation is not essential for TRPM5 expression at the cell surface. The faint upper band observed in lanes 4 and 6 of Figure 4B may represent endogenous TRPM5 expressed in HEK293 cells. 
A 0 .

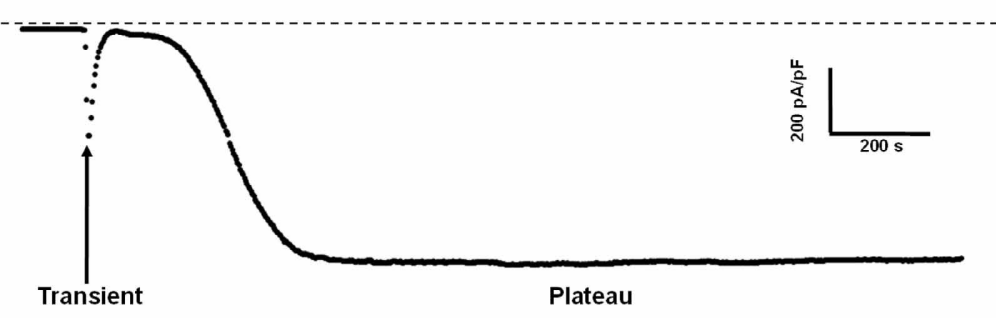

B

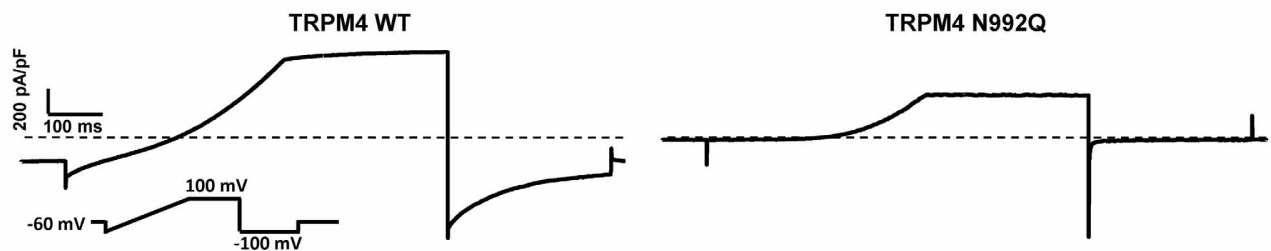

C

Transient

Plateau
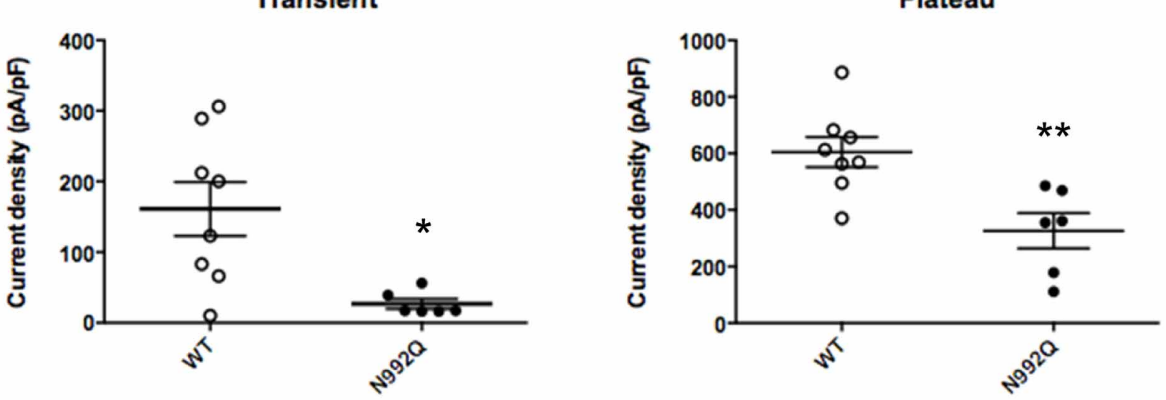

D

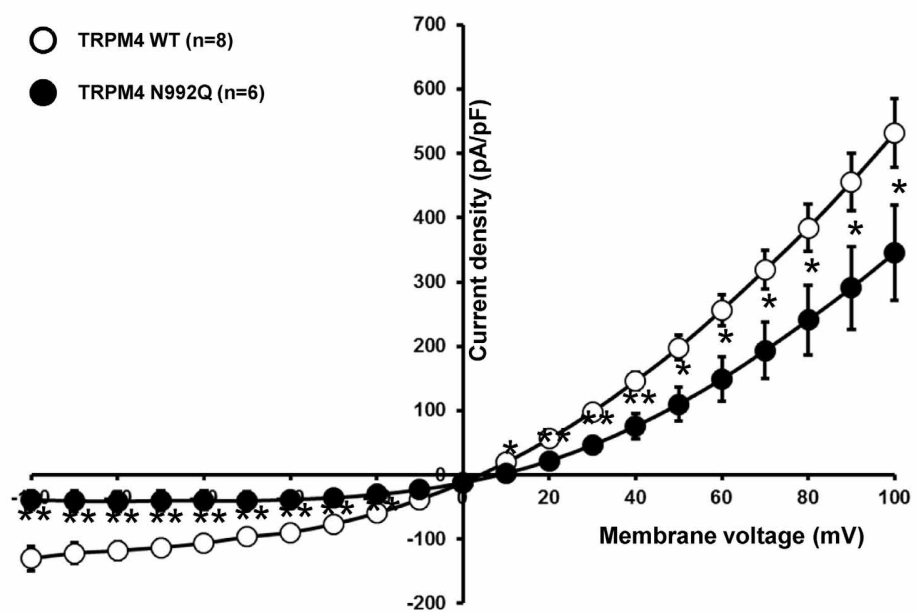

FIGURE 3 | Whole cell patch clamp recording of WT and TRPM4 N992Q mutant transiently transfected in HEK293 cells. (A) Current density of TRPM4 over time shows a brief transient and a long persistent plateau phase. (B) Individual currents recorded using a ramp protocol depicted in the inset. (C) Quantification at $+100 \mathrm{mV}$ of WT and TRPM4 N992O mutant current densities during the transient (left panel) and plateau (right panel) phases in dot plot graph shows a significant decrease in current densities in both phases compared to TRPM4 WT. (D) Current vs. voltage relationship shows a decreased current in TRPM4 N9920 mutant without major alterations of the voltage-dependence. Statistical test using two-tailed Student $T$-test $* P<0.05$, ** $P<0.01$.

\section{TRPM5 N-GLYCOSYLATION TYPES ARE SIMILAR IN THE} INTRACELLULAR FRACTION AND AT THE CELL SURFACE

To learn more about the glycosylation identity of TRPM5, TRPM5 was treated with Endo $\mathrm{H}$ in addition to PNGase F, as was done for TRPM4. While PNGase F completely trimmed TRPM5 (Figure 4C lanes 4 and 8), Endo $\mathrm{H}$ only trimmed a small fraction of TRPM5 (Figure 4C lanes 3 and 7). Since no differences in the patterns between total and biotinylated fractions were observed, 

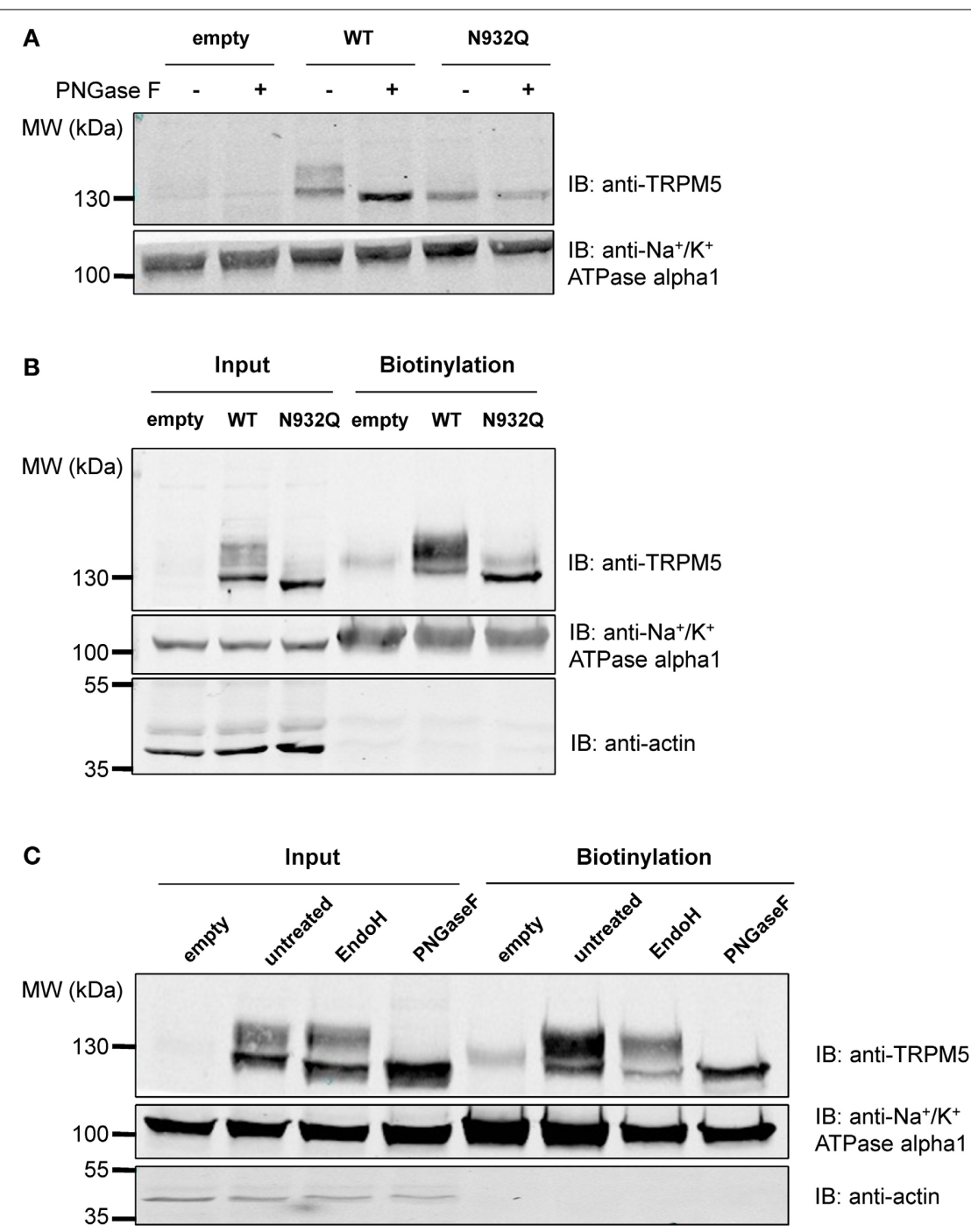

FIGURE 4 | Deglycosylation and biotinylation of TRPM5. (A) Treatment with PNGase F demonstrates that unglycosylated WT TRPM5 has a similar molecular weight to the TRPM5 N932O mutant. (B) Cell surface biotinylation of HEK293 cells transiently transfected with WT or
TRPM5 N9320 mutant constructs shows expression of both WT and mutant at the total level and at the cell surface. (C) Treatment with Endo $\mathrm{H}$ removes some of the glycosylation in both input and biotinylated fractions.
TRPM5 was concluded to have a majority of complex oligosaccharides with some minor amounts of high mannose and hybrid oligosaccharides in both fractions.

\section{TRPM5 CURRENT DENSITY IS DECREASED WITH THE N9320 MUTANT}

Functional experiments using the similar patch clamp technique as was done for TRPM4 were performed. In the case of TRPM5, only one phase was observed after rupture of the membrane patch. The recordings revealed a statistically significant decrease in the current density at $+100 \mathrm{mV}$ for the N932Q mutant compared to WT (WT vs. N932Q: $848 \pm 55 \mathrm{pA} / \mathrm{pF} n=5$ vs. $136 \pm 26 \mathrm{pA} / \mathrm{pF} n=5$ ) (Figures 5A,B). No major alterations in the biophysical properties were observed (Figure 5B).

\section{TUNICAMYCIN TREATMENT INCREASES TRPM4 CURRENT DENSITY}

Since the TRPM4 N992Q mutation reduced its current without any striking biophysical alterations, it remained to be determined whether the effect was primarily dependent on the Asn to Gln mutation itself or on the consequence of the mutation, i.e., the lack of TRPM4 glycosylation. Thus, HEK293 cells transiently expressing either WT TRPM4 or N992Q mutant were treated with tunicamycin, an inhibitor of N-linked glycan synthesis. Tunicamycin treatment at $10 \mu \mathrm{g} / \mathrm{ml}$ for $19 \mathrm{~h}$ decreased the upper band by approximately $60 \%$, as shown in Figure 6A. Somewhat unexpectedly, this treatment led to a statistically significant increase in both the transient and plateau current densities of TRPM4 WT (normalized untreated vs. treated transient; $100 \pm 27 \% n=5$ vs. $494 \pm 129 \% n=5$ and plateau; $100 \pm$ $6 \% n=5$ vs. $202 \pm 29 \% n=5$ ) (Figure 6B) without modifying the I-V relationship (Figure $6 \mathrm{C}$ ) or the deactivation kinetics at $+100 \mathrm{mV}$ (WT DMSO $4855 \pm 379 \mathrm{pA} / \mathrm{s} n=5$ vs. WT tunicamycin $5265 \pm 572 \mathrm{pA} / \mathrm{s} n=5, p>0.05)$. Importantly, the same treatment on HEK293 cells expressing TRPM4 N992Q neither altered the current density recorded during both phases 


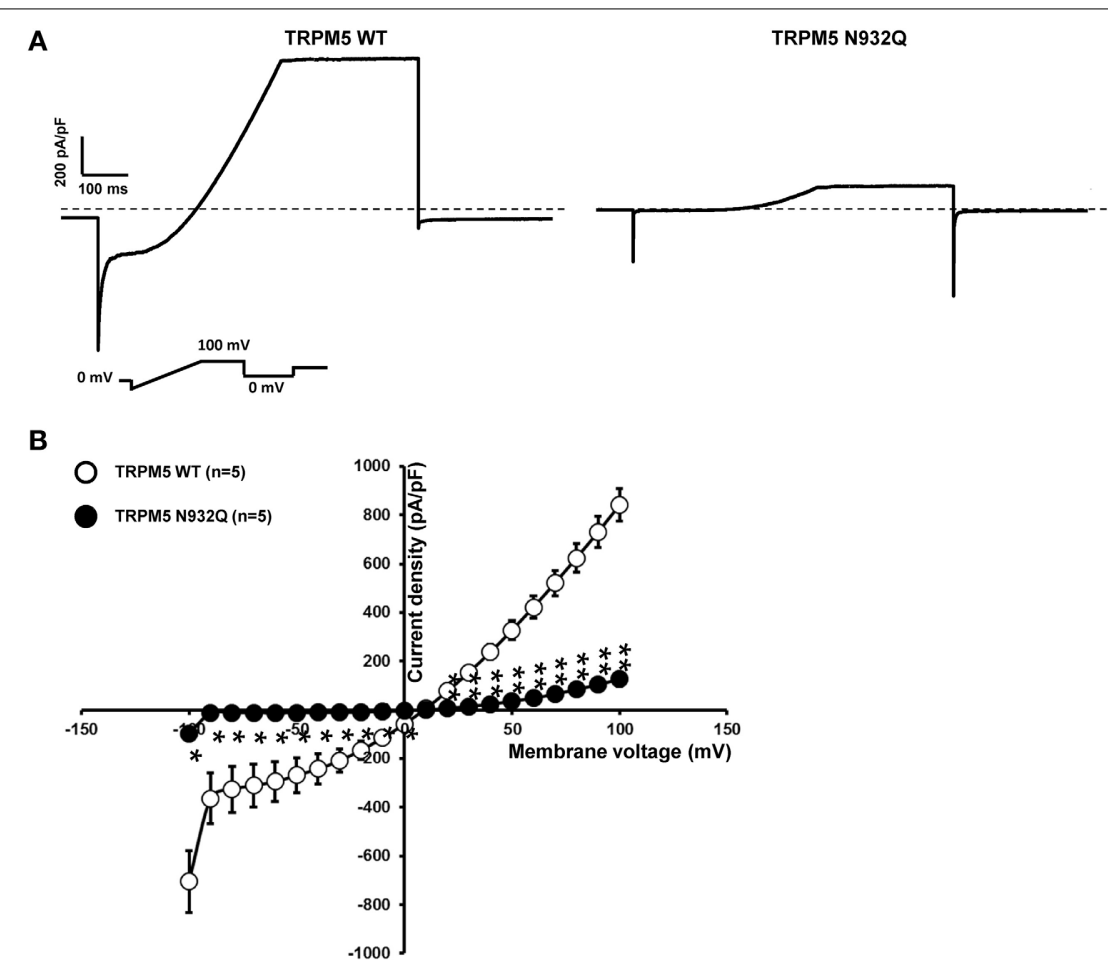

FIGURE 5 | Whole cell patch clamp recording of WT and TRPM5 N9320 mutant transiently transfected in HEK293 cells. (A) Individual currents recorded using a ramp protocol depicted in the inset. (B) Current vs. voltage relationship shows a decreased current in TRPM5 N9320 mutant without major alterations of the biophysical properties. Statistical test using two-tailed Student $T$-test $* P<0.05,{ }^{* *} P<0.01$. (untreated vs. treated transient; $100 \pm 26 \% n=5$ vs. $102 \pm 40 \%$ $n=6$ and plateau; $100 \pm 31 \% n=5$ vs. $92 \pm 18 \% n=6)$ nor the I-V relationship (Figures 6B,C). This suggests that the observed current density increase with TRPM4 WT under tunicamycin treatment is dependent on glycosylation of Asn ${ }^{992}$ (Figures 6A,B) and indicates that the N992Q-mediated current decrease depends on the mutation itself.

\section{DISCUSSION}

The main finding of this study is that in heterologous expression systems TRPM4 and TRPM5 are N-linked glycosylated, while TRPM4 was also found to be glycosylated in cardiac tissues. Furthermore, it was observed that this N-glycosylation occurs (1) via a unique site located in the pore-forming region, (2) may not play a significant role in trafficking to the plasma membrane, (3) can be of different types, and (4) is involved in modulating the current density at the cell surface.

\section{GLYCOSYLATION OF TRPM4/5 CHANNELS}

The pore region of the TRP channel, known to harbor the selectivity filter, may appear to be an unusual site for glycosylation. Several recent reports, however, have shown that TRPV1 and TRPV4 also have a unique $\mathrm{N}$-glycosylation site in the same domain (Xu et al., 2006; Veldhuis et al., 2012). Furthermore, as cited by Cohen (2006), TRPV2 and TRPV3 are predicted to have $\mathrm{N}$-glycosylation sites in the same region. Very recently, Woo et al. (2013a) investigated the site and the role of N-linked glycosylation of the mouse TRPM4. They showed biochemical evidence for TRPM4 glycosylation in native rat tissues, suggesting that this post-translational modification likely plays an important role in vivo. In the present work, we obtained evidence that fullyand core glycosylated forms of TRPM4 are expressed in human cardiac atrial tissue.

\section{FORWARD TRAFFICKING AND GLYCOSYLATION}

$\mathrm{N}$-linked protein glycosylation has been shown to be crucial for the trafficking of several ion channels toward the plasma membrane, i.e., Kv11.1 (hERG channel) (Petrecca et al., 1999) and Shaker channels (Khanna et al., 2001). In contrast, despite not having glycosylation, mutant TRPM4/5 and WT TRPM4/5 from tunicamycin-treated cells were well expressed at the plasma membrane, suggesting that $\mathrm{N}$-glycosylation may not play an essential role in the forward trafficking. Woo and co-workers recently came to a similar conclusion (Woo et al., 2013a). Others have also reported that glycosylation is not essential for the forward trafficking of membrane proteins, such as TRPV5 (Leunissen et al., 2013), organic solute transporter alpha (Soroka et al., 2008) and proline-rich membrane anchor (Chan et al., 2012). In addition to the regulation of forward trafficking, N-glycosylation most likely has other important cellular functions, such as cell adhesion, self/non-self-recognition, receptor activation and endocytosis (Ohtsubo and Marth, 2006).

\section{COMPLEX OLIGOSACCHARIDES AND THEIR ROLE IN TRPM4/5 REGULATION}

As shown in Figure 2C, we observed that TRPM4 can have different types of $\mathrm{N}$-glycosylation in the intracellular fraction 


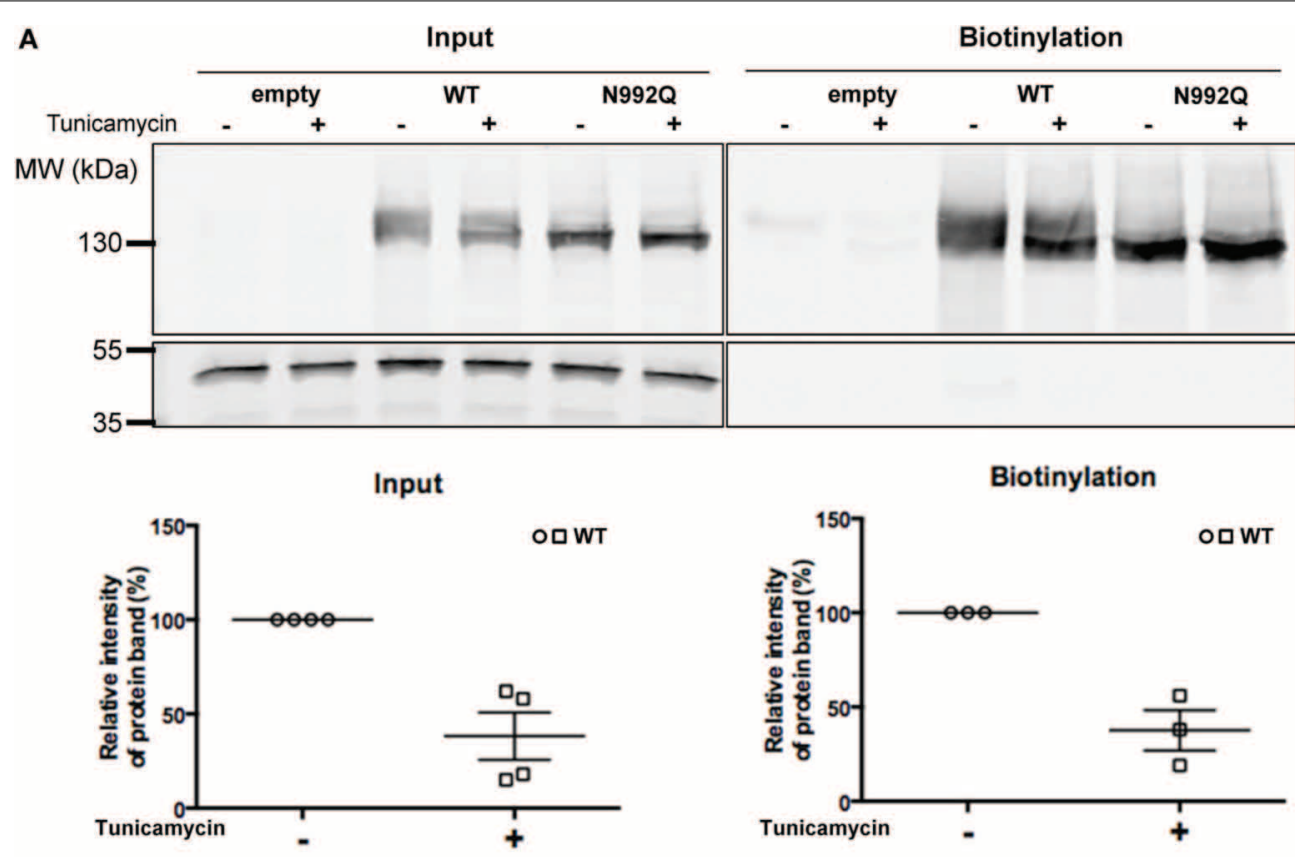

B
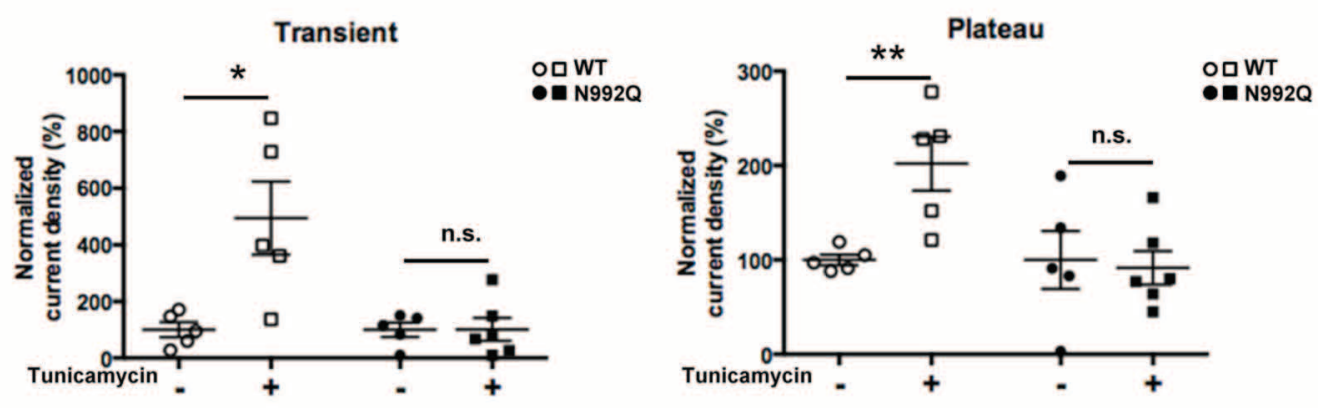

C

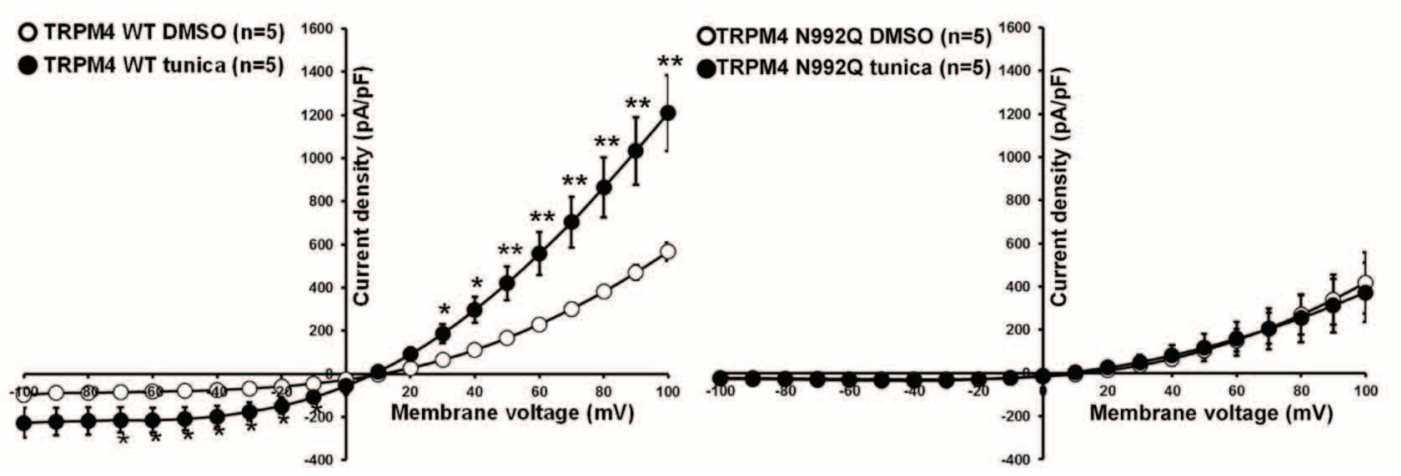

FIGURE 6 | Effect of tunicamycin treatment on WT and TRPM4 N9920 mutants. (A) Cell surface biotinylation of HEK293 cells transiently transfected with WT or TRPM4 N992O mutant constructs and pretreated with tunicamycin $(10 \mu \mathrm{g} / \mathrm{ml} ; 19 \mathrm{~h})$ demonstrates a reduction of the glycosylated bands of TRPM4 following the treatment. Western blots shown in upper panels with quantification in lower panels (treated $38 \pm 13 \%$ vs. untreated $100 \pm 00 \% n=4$ in the input fraction; treated $38 \pm 11 \%$ vs. untreated $100 \pm 00 \% n=3$ in the biotinylated fraction; $p<0.05$ ) (B) Quantification in dot plot graph of WT and N992Q mutant current densities at $+100 \mathrm{mV}$ shows a significant increase in the transient and plateau current densities after tunicamycin treatment $(10 \mu \mathrm{g} / \mathrm{ml} ; 19 \mathrm{~h})$ only with the WT (transient: untreated $123 \pm 37 \mathrm{pA} / \mathrm{pF} n=5$ vs. treated $610 \pm 178 \mathrm{pA} / \mathrm{pF}$ $n=5 ; p<0.05$; plateau: untreated $657 \pm 41 \mathrm{pA} / \mathrm{pF} n=5$ vs. treated $1327 \pm$ $210 \mathrm{pA} / \mathrm{pF} n=5 ; p<0.05$ ), but not with the $\mathrm{N} 992 \mathrm{Q}$ mutant (transient: untreated $23 \pm 6 \mathrm{pA} / \mathrm{pF} n=5$ vs. treated $23 \pm 10 \mathrm{pA} / \mathrm{pF} n=6$; plateau untreated $426 \pm 147 \mathrm{pA} / \mathrm{pF} n=5$ vs. treated $391 \pm 83 \mathrm{pA} / \mathrm{pF} n=6)$. Untreated: vehicle (DMSO). (C) Current vs. voltage relationship shows an increase of current in TRPM4 WT condition after tunicamycin treatment, without major alterations in voltage dependence. Statistical test using two-tailed Student $T$-test ${ }^{*} P<0.05,{ }^{*} P<0.01$. 
(with a significant amount of complex oligosaccharides and a minor amount of high mannose and/or hybrid oligosaccharides), and at the cell surface (exclusively with complex oligosaccharides). Woo et al. (2013a) also showed analogous results for the total protein fraction, although they only mentioned the presence of high mannose in TRPM4. The significant amount of complex oligosaccharides found in the total fraction (intracellular), which are a mix of cytoplasm, endoplasmic reticulum (ER), Golgi apparatus, plasma membrane might come from the bulk TRPM4 Golgi and/or downstream compartments where TRPM4 is mostly glycosylated with complex oligosaccharides. Nonetheless, we cannot rule out the possibility that ER membranes were not efficiently disrupted to release ER-bound TRPM4 which is most likely glycosylated with high mannose and/or oligosaccharides. Such a difference of glycosylation types in the two fractions was, however, not observed with TRPM5, despite the fact that the site of glycosylation is found in a homologous domain. It is also interesting to note that most membrane proteins are glycosylated with complex oligosaccharides, but not with high mannose and/or hybrid oligosaccharides at the cell surface. However, we observed that TRPM5 is glycosylated with a significant amount of complex oligosaccharides and a minor amount of high mannose and hybrid oligosaccharides both intracellularly and at the cell surface. Others groups (Tulsiani et al., 1992; Kuo et al., 1996; Meschi et al., 2005), however, have found high mannose and/or hybrid oligosaccharides on plasma membrane-bound proteins. Taking these observations into account, it is possible to find TRPM5 glycosylated with high mannose and/or hybrid oligosaccharides at the cell surface.

\section{UNGLYCOSYLABLE TRPM4/5 MUTANTS}

In the present study, the consequences of the Asn to Gln mutations on the function of the TRPM4/5 channels were further investigated. The unglycosylable TRPM4/5 mutants displayed strikingly decreased current amplitudes compared to their respective controls, despite the fact that their total protein expression at the cell surface was not altered. This finding suggests that $\mathrm{N}$-glycosylation of TRPM4/5 has a stronger impact on the channel's function than on its expression at the plasma membrane. Nevertheless, the observed discrepancy between the biochemistry and functional findings is puzzling. It may be that the decreased TRPM4/5 current densities are caused by the mutation itself, rather than by the fact that the channels are not glycosylated. Woo et al. (2013a) showed that the single channel conductance of the mouse TRPM4 channel, which harbors the homologous Asn to Gln mutation, was not altered. It may be, however, that the observed whole-cell current reduction could be due to alterations of open probability that were not measured by the authors.

\section{TUNICAMYCIN TREATMENT OF WT AND UNGLYCOSYLABLE TRPM4}

Since the N-glycoslyation signal $\left(\mathrm{Asn}^{992}\right)$ of TRPM4 is close to its selectivity filter, the observed current decrease with the N992Q mutant could be due to either an alteration of TRPM4 gating mediated directly by the mutation itself or as a consequence of absence of glycosylation. To discriminate between these two possibilities, TRPM4 currents were recorded after treating the cells with the glycosylation inhibitor, tunicamycin, in order to determine whether the reduction of the TRPM4 N992Q current amplitude was mainly a consequence of the lack of glycosylation. Somewhat unexpectedly, following this treatment both plateau and transient TRPM4-mediated current densities were greater, without any evidence of an increase in the number of channels expressed at the plasma membrane. Importantly, tunicamycin had no effect on the unglycosylable TRPM4 N992Q mutant. This finding suggests (1) that the tunicamycin-mediated current increase was due to the deglycosylation of the channel rather than the altered glycosylation of other proteins, and (2) that the N992Q-induced reduction of current was caused by the mutation itself rather than its effect on glycosylation. As a consequence, these results indicate that the N992Q mutant is not the most suitable model for the investigation of the functional roles of TRPM4 glycosylation. Analogous to the aforementioned reduction in the current of the unglycosylable mutants, the intensity of the total TRPM4 protein signal at the cell surface (both fully- and core glycosylated TRPM4) was not increased after tunicamycin treatment, while the current density was augmented. These discrepant observations may be due to limitations of the technique. As observed in Figure 6A, when compared to the untreated condition, the tunicamycin treatment decreased the fully glycosylated band of TRPM4 WT and increased the intensity of the core $\mathrm{N}$-glycosylated band. A similar observation was also made by Leunissen et al. (2013) after Endo F treatment of WT TRPV5. It is possible that under these conditions the quantification of the TRPM4 signal is biased because the affinity of the antibody may vary depending on the N-glycosylation pattern, as has been previously suggested (Reynard et al., 2004). Another explanation of this discrepancy could be that the TRPM4 single channel properties are altered after tunicamycin treatment.

\section{CONCLUSIONS}

Altogether, the results presented in this study demonstrate that N-linked glycosylation at a unique site on both TRPM4 and TRPM5 is involved in the regulation of channel activity. Additionally, these results also suggest that the region surrounding the selectivity filter (Nilius et al., 2005a) is involved in the channel's function. Further experiments are needed to better understand the role of this unique glycosylation site in modulating the biophysical properties of both TRPM4 and TRPM5 channels. In summary, we have mapped the N-glycosylation site of TRPM4/5 and have identified the types of N-glycosylation displayed by both channels. More importantly, we were able to demonstrate that glycosylation impacts channel function but not its surface expression.

\section{AUTHOR CONTRIBUTIONS}

Ninda Syam designed, performed experiments and wrote the manuscript. Jean-Sébastien Rougier designed, performed experiments and wrote the manuscript. Hugues Abriel designed and supervised the project and wrote the manuscript.

\section{ACKNOWLEDGMENTS}

This work was supported by a grant from the Swiss National Science Foundation to Hugues Abriel (310030B_147060), the TransCure NCCR network, and the Berne University Research 
Foundation. We thank Dr. A. Felley and the members of Hugues Abriel's group for their help and useful comments on this manuscript. We also thank Dr. H. Most, and Prof. T. Carrel from the Bern University Hospital for providing human cardiac atrial samples.

\section{REFERENCES}

Abriel, H., Syam, N., Sottas, V., Amarouch, M. Y., and Rougier, J. S. (2012). TRPM4 channels in the cardiovascular system: physiology, pathophysiology, and pharmacology. Biochem. Pharmacol. 84, 873-881. doi: 10.1016/j.bcp. 2012.06.021

Amarouch, M. Y., Syam, N., and Abriel, H. (2013). Biochemical, singlechannel, whole-cell patch clamp, and pharmacological analyses of endogenous TRPM4 channels in HEK293 cells. Neurosci. Lett. 541, 105-110. doi: 10.1016/j.neulet.2013.02.011

Barbet, G., Demion, M., Moura, I. C., Serafini, N., Leger, T., Vrtovsnik, F., et al. (2008). The calcium-activated nonselective cation channel TRPM4 is essential for the migration but not the maturation of dendritic cells. Nat. Immunol. 9, 1148-1156. doi: 10.1038/ni.1648

Chan, W. K., Chen, V. P., Luk, W. K., Choi, R. C., and Tsim, K. W. (2012). N-linked glycosylation of proline-rich membrane anchor (PRiMA) is not required for assembly and trafficking of globular tetrameric acetylcholinesterase. Neurosci. Lett. 523, 71-75. doi: 10.1016/j.neulet.2012.06.045

Cheng, H., Beck, A., Launay, P., Gross, S. A., Stokes, A. J., Kinet, J. P., et al. (2007). TRPM4 controls insulin secretion in pancreatic beta-cells. Cell Calcium 41, 51-61. doi: 10.1016/j.ceca.2006.04.032

Clapham, D. E., Julius, D., Montell, C., and Schultz, G. (2005). International union of pharmacology. XLIX. Nomenclature and structure-function relationships of transient receptor potential channels. Pharmacol. Rev. 57, 427-450. doi: 10.1124/pr.57.4.6

Cohen, D. M. (2006). Regulation of TRP channels by N-linked glycosylation. Semin. Cell Dev. Biol. 17, 630-637. doi: 10.1016/j.semcdb.2006.11.007

Crnich, R., Amberg, G. C., Leo, M. D., Gonzales, A. L., Tamkun, M. M., Jaggar, J. H., et al. (2010). Vasoconstriction resulting from dynamic membrane trafficking of TRPM4 in vascular smooth muscle cells. Am. J. Physiol. Cell Physiol. 299, C682-C694. doi: 10.1152/ajpcell.00101.2010

Demion, M., Bois, P., Launay, P., and Guinamard, R. (2007). TRPM4, a $\mathrm{Ca} 2+$-activated nonselective cation channel in mouse sino-atrial node cells. Cardiovasc. Res. 73, 531-538. doi: 10.1016/j.cardiores.2006.11.023

Earley, S., Straub, S. V., and Brayden, J. E. (2007). Protein kinase C regulates vascular myogenic tone through activation of TRPM4. Am. J. Physiol. Heart Circ. Physiol. 292, H2613-H2622. doi: 10.1152/ajpheart.01286.2006

Egorov, A. V., Hamam, B. N., Fransen, E., Hasselmo, M. E., and Alonso, A. A. (2002). Graded persistent activity in entorhinal cortex neurons. Nature 420, 173-178. doi: 10.1038/nature01171

Egorov, A. V., Unsicker, K., and von Bohlen und Halbach, O. (2006). Muscarinic control of graded persistent activity in lateral amygdala neurons. Eur. J. Neurosci. 24, 3183-3194. doi: 10.1111/j.1460-9568.2006.05200.x

Gonzales, A. L., Garcia, Z. I., Amberg, G. C., and Earley, S. (2010). Pharmacological inhibition of TRPM4 hyperpolarizes vascular smooth muscle. Am. J. Physiol. Cell Physiol. 299, C1195-C1202. doi: 10.1152/ajpcell.00269.2010

Guinamard, R. (2007). Determination of channel properties at the unitary level in adult mammalian isolated cardiomyocytes. Methods Mol. Biol. 403, 195-209. doi: 10.1007/978-1-59745-529-9_13

Guinamard, R., Demion, M., Chatelier, A., and Bois, P. (2006a). Calcium-activated nonselective cation channels in mammalian cardiomyocytes. Trends Cardiovasc. Med. 16, 245-250. doi: 10.1016/j.tcm.2006.04.007

Guinamard, R., Demion, M., Magaud, C., Potreau, D., and Bois, P. (2006b). Functional expression of the TRPM4 cationic current in ventricular cardiomyocytes from spontaneously hypertensive rats. Hypertension 48, 587-594. doi 10.1161/01.HYP.0000237864.65019.a5

Khanna, R., Myers, M. P., Laine, M., and Papazian, D. M. (2001). Glycosylation increases potassium channel stability and surface expression in mammalian cells. J. Biol. Chem. 276, 34028-34034. doi: 10.1074/jbc.M105248200

Kim, Y. S., Kang, E., Makino, Y., Park, S., Shin, J. H., Song, H., et al. (2013). Characterizing the conductance underlying depolarization-induced slow current in cerebellar Purkinje cells. J. Neurophysiol. 109, 1174-1181. doi: $10.1152 /$ jn. 01168.2011
Kruger, J., Kunert-Keil, C., Bisping, F., and Brinkmeier, H. (2008). Transient receptor potential cation channels in normal and dystrophic $\mathrm{mdx}$ muscle. Neuromuscul. Disord. 18, 501-513. doi: 10.1016/j.nmd.2008.04.003

Kruse, M., Schulze-Bahr, E., Corfield, V., Beckmann, A., Stallmeyer, B., Kurtbay, G. et al. (2009). Impaired endocytosis of the ion channel TRPM4 is associated with human progressive familial heart block type I. J. Clin. Invest. 119, 2737-2744. doi: $10.1172 / \mathrm{JCI} 38292$

Kuo, C., Takahashi, N., Swanson, A. F., Ozeki, Y., and Hakomori, S. (1996). An $\mathrm{N}$-linked high-mannose type oligosaccharide, expressed at the major outer membrane protein of Chlamydia trachomatis, mediates attachment and infectivity of the microorganism to HeLa cells. J. Clin. Invest. 98, 2813-2818. doi: 10.1172/JCI119109

Launay, P., Cheng, H., Srivatsan, S., Penner, R., Fleig, A., and Kinet, J. P. (2004). TRPM4 regulates calcium oscillations after $\mathrm{T}$ cell activation. Science 306, 1374-1377. doi: 10.1126/science.1098845

Leunissen, E. H., Nair, A. V., Bull, C., Lefeber, D. J., van Delft, F. L., Bindels, R. J., et al. (2013). The epithelial calcium channel TRPV5 is regulated differentially by Klotho and Sialidase. J. Biol. Chem. 288, 29238-29246. doi: 10.1074/jbc.M113.473520

Liu, H., El Zein, L., Kruse, M., Guinamard, R., Beckmann, A., Bozio, A., et al. (2010). Gain-of-function mutations in TRPM4 cause autosomal dominant isolated cardiac conduction disease. Circ. Cardiovasc. Genet. 3, 374-385. doi: 10.1161/CIRCGENETICS.109.930867

Maley, F., Trimble, R. B., Tarentino, A. L., and Plummer, T. H. Jr. (1989). Characterization of glycoproteins and their associated oligosaccharides through the use of endoglycosidases. Anal. Biochem. 180, 195-204. doi: 10.1016/00032697(89)90115-2

Mathar, I., Kecskes, M., Van der Mieren, G., Jacobs, G., Uhl, S., Camacho Londono, J. E., et al. (2013). Increased ss-Adrenergic Inotropy in Ventricular Myocardium from Trpm4-/- Mice. Circ. Res. 114, 283-294. doi: 10.1161/CIRCRESAHA114.302835

Mathar, I., Vennekens, R., Meissner, M., Kees, F., Van der Mieren, G., Camacho Londono, J. E., et al. (2010). Increased catecholamine secretion contributes to hypertension in TRPM4-deficient mice. J. Clin. Invest. 120, 3267-3279. doi: 10.1172/JCI41348

Meschi, J., Crouch, E. C., Skolnik, P., Yahya, K., Holmskov, U., Leth-Larsen, R., et al. (2005). Surfactant protein D binds to human immunodeficiency virus (HIV) envelope protein gp120 and inhibits HIV replication. J. Gen. Virol. 86, 3097-3107. doi: 10.1099/vir.0.80764-0

Murakami, M., Xu, F., Miyoshi, I., Sato, E., Ono, K., and Iijima, T. (2003). Identification and characterization of the murine TRPM4 channel. Biochem. Biophys. Res. Commun. 307, 522-528. doi: 10.1016/S0006-291X(03) 01186-0

Nilius, B., Prenen, J., Janssens, A., Owsianik, G., Wang, C., Zhu, M. X., et al. (2005a). The selectivity filter of the cation channel TRPM4. J. Biol. Chem. 280, 22899-22906. doi: 10.1074/jbc.M501686200

Nilius, B., Prenen, J., Tang, J., Wang, C., Owsianik, G., Janssens, A., et al. (2005b). Regulation of the Ca2+ sensitivity of the nonselective cation channel TRPM4. J. Biol. Chem. 280, 6423-6433. doi: 10.1074/jbc.M411089200

Nilius, B., Prenen, J., Voets, T., and Droogmans, G. (2004). Intracellular nucleotides and polyamines inhibit the Ca2+-activated cation channel TRPM4b. Pflugers Arch. 448, 70-75. doi: 10.1007/s00424-003-1221-x

Ohtsubo, K., and Marth, J. D. (2006). Glycosylation in cellular mechanisms of health and disease. Cell 126, 855-867. doi: 10.1016/j.cell.2006.08.019

Petrecca, K., Atanasiu, R., Akhavan, A., and Shrier, A. (1999). N-linked glycosylation sites determine HERG channel surface membrane expression. J. Physiol. 515(pt 1), 41-48. doi: 10.1111/j.1469-7793.1999. 041ad.x

Ramsey, I. S., Delling, M., and Clapham, D. E. (2006). An introduction to TRP channels. Annu. Rev. Physiol. 68, 619-647. doi: 10.1146/annurev.physiol.68. 040204.100431

Reynard, F., Fatmi, A., Verrier, B., and Bedin, F. (2004). HIV-1 acute infection env glycomutants designed from 3D model: effects on processing, antigenicity, and neutralization sensitivity. Virology 324, 90-102. doi: 10.1016/j.virol.2004. 03.022

Schattling, B., Steinbach, K., Thies, E., Kruse, M., Menigoz, A., Ufer, F., et al. (2012). TRPM4 cation channel mediates axonal and neuronal degeneration in experimental autoimmune encephalomyelitis and multiple sclerosis. Nat. Med. 18, 1805-1811. doi: $10.1038 / \mathrm{nm} .3015$ 
Shimizu, T., Owsianik, G., Freichel, M., Flockerzi, V., Nilius, B., and Vennekens, R. (2009). TRPM4 regulates migration of mast cells in mice. Cell Calcium 45, 226-232. doi: 10.1016/j.ceca.2008.10.005

Simard, J. M., Kahle, K. T., and Gerzanich, V. (2010). Molecular mechanisms of microvascular failure in central nervous system injury-synergistic roles of NKCC1 and SUR1/TRPM4. J. Neurosurg. 113, 622-629. doi: 10.3171/2009.11.JNS081052

Soroka, C. J., Xu, S., Mennone, A., Lam, P., and Boyer, J. L. (2008). N-Glycosylation of the alpha subunit does not influence trafficking or functional activity of the human organic solute transporter alpha/beta. BMC Cell Biol. 9:57. doi: 10.1186/1471-2121-9-57

Teruyama, R., Sakuraba, M., Kurotaki, H., and Armstrong, W. E. (2011). Transient receptor potential channel $\mathrm{m} 4$ and $\mathrm{m} 5$ in magnocellular cells in rat supraoptic and paraventricular nuclei. J. Neuroendocrinol. 23, 1204-1213. doi: 10.1111/j.1365-2826.2011.02211.x

Tulsiani, D. R., Nagdas, S. K., Cornwall, G. A., and Orgebin-Crist, M. C. (1992). Evidence for the presence of high-mannose/hybrid oligosaccharide chain(s) on the mouse ZP2 and ZP3. Biol. Reprod. 46, 93-100. doi: 10.1095/biolreprod46.1.93

Veldhuis, N. A., Lew, M. J., Abogadie, F. C., Poole, D. P., Jennings, E. A., Ivanusic, J. J., et al. (2012). N-glycosylation determines ionic permeability and desensitization of the TRPV1 capsaicin receptor. J. Biol. Chem. 287, 21765-21772. doi: 10.1074/jbc.M112.342022

Woo, S. K., Kwon, M. S., Ivanov, A., Geng, Z., Gerzanich, V., and Simard, J. M. (2013a). Complex N-glycosylation stabilizes surface expression of transient receptor potential melastatin 4b. J. Biol. Chem. 288, 36409-36417. doi: 10.1074/jbc.M113.530584
Woo, S. K., Kwon, M. S., Ivanov, A., Gerzanich, V., and Simard, J. M. (2013b). The sulfonylurea receptor 1 (Sur1)-transient receptor potential melastatin 4 (Trpm4) channel. J. Biol. Chem. 288, 3655-3667. doi: 10.1074/jbc.M112.428219

$\mathrm{Xu}, \mathrm{H} ., \mathrm{Fu}, \mathrm{Y} ., \mathrm{Tian}, \mathrm{W}$. , and Cohen, D. M. (2006). Glycosylation of the osmoresponsive transient receptor potential channel TRPV4 on Asn-651 influences membrane trafficking. Am. J. Physiol. Renal. Physiol. 290, F1103-F1109. doi: 10.1152/ajprenal.00245.2005

Zhang, Z., Zhao, Z., Margolskee, R., and Liman, E. (2007). The transduction channel TRPM5 is gated by intracellular calcium in taste cells. J. Neurosci. 27, 5777-5786. doi: 10.1523/JNEUROSCI.4973-06.2007

Conflict of Interest Statement: The authors declare that the research was conducted in the absence of any commercial or financial relationships that could be construed as a potential conflict of interest.

Received: 28 November 2013; accepted: 06 February 2014; published online: 24 February 2014.

Citation: Syam N, Rougier J-S and Abriel H (2014) Glycosylation of TRPM4 and TRPM5 channels: molecular determinants and functional aspects. Front. Cell. Neurosci. 8:52. doi: 10.3389/fncel.2014.00052

This article was submitted to the journal Frontiers in Cellular Neuroscience. Copyright (C) 2014 Syam, Rougier and Abriel. This is an open-access article distributed under the terms of the Creative Commons Attribution License (CC BY). The use, distribution or reproduction in other forums is permitted, provided the original author(s) or licensor are credited and that the original publication in this journal is cited, in accordance with accepted academic practice. No use, distribution or reproduction is permitted which does not comply with these terms. 